\title{
Área Alterada pela Ocupação de Posseiros em Marãiwatsédé, Terra
}

\section{Indígena Xavante}

\author{
Rea Altered by the Occupation of Posters in Mariwatsédé, Xavante Indigenous Land
}

\author{
Raphael Maia Aveiro Cessa ${ }^{1}$ \\ Doutor em Agronomia pela UFGD \\ Professor do IFB - campus Planaltina - Área Agronomia \\ e-mail: raphael.cessa@ifb.edu.br
}

\begin{abstract}
Resumo: Este trabalho objetivou quantificar a área alterada pela ocupação de posseiros em Marãiwatsédé, terra indígena Xavante localizada no Estado de Mato Grosso, Brasil, entre o período 1992 a 2013. A terra indígena Xavante Marãiwatsédé tem área de 165.770,99 hectares, localizada nos municípios São Félix do Araguaia, Alto Boa vista e Bom Jesus do Araguaia. A área delimitada deu-se a partir da Orbita 224, Ponto 68, do Satélite LANSAT 5. A identificação e quantificação da ocupação das áreas da terra indígena Xavante Marãiwatsédé deu-se por meio de mapas considerando as classes temáticas: complexo vegetativo (Florestas, Mata de galeria, Cerrado típico, Várzeas e áreas alteradas mas em processo de regeneração natural); áreas alteradas (utilizadas com agricultura e/ou pecuária). No ano de 1992 havia na terra indígena Marãiwatsédé 23,24\% de áreas alteradas por uso de atividades agrícolas e/ou pecuárias, e 76,76\% de complexo vegetativo. No ano da sua desintrusão, em 2013, a referida terra indígena continha $66,64 \%$ de áreas alteradas e 33,36\% de complexo vegetativo. A taxa de alteração das áreas de Marãiwatsédé no período entre 1992, ano da ocupação por posseiros, e 2013, ano da desintrusão foi de 2,07\% ano ${ }^{-1}$, área equivalente a $3.431,45$ hectares. Com isso constatou-se que a ocupação de Marãiwatsédé culminou na redução de 43,40\% do complexo vegetativo inicial.
\end{abstract}

Palavras-chave: Desintrusão; Área alterada; Posseiros.

Abstract: This work aimed to quantify the area altered by the occupation of squatters in Marãiwatsédé, a Xavante indigenous land located in the State of Mato Grosso, Brazil, between 1992 and 2013. The Xavante Marãiwatsédé indigenous land covers an area of 165,770.99 hectares, located in the São Felix do Araguaia, Alto Boa Vista and Bom Jesus do Araguaia. The area defined was based on Orbita 224, Point 68, of the satellite LANSAT 5. The identification and quantification of the occupation of the areas of the indigenous Xavante Marãiwatsédé land was made by means of maps considering the thematic classes: vegetative complex (Forests, Gallery forest, typical Cerrado, floodplains and altered areas but in process of natural regeneration); Altered areas (used with agriculture and / or livestock). In the year 1992 there were 23,24\% of areas affected by agricultural and / or livestock activities in the Marãiwatsédé indigenous land and $76.76 \%$ of the vegetation complex. In the year of its disinfusion, in 2013, said indigenous land contained $66.64 \%$ of altered areas and $33.36 \%$ of vegetative complex. The rate of change in the areas of Marãiwatsédé in the period between 1992, year of occupation by squatters, and 2013, year of disintrusion was $2.07 \%$ year-1, an area equivalent to $3,431.45$ hectares. With this it was verified that the occupation of Marãiwatsédé culminated in the reduction of $43.40 \%$ of the initial vegetative complex.

Keywords: Disinfection; Altered area; Squatters. 


\section{Introdução}

Na década de 60 o grupo paulista Ometto adquiriu até o ano de 1972, uma fazenda denominada Suiá-Missu com mais de 1.000 .000 ha por meio de incentivos fiscais fomentados pela Superintendência do Desenvolvimento da Amazônia (SUDAM) para desenvolvimento dos projetos agropecuários amazônicos. Nesse ano o referido grupo transferiu a Suiá-Missu à Liquigás (URSINI). Isso porque o grupo URSINI pretendia fazer da área adquirida um empreendimento modelo criando a cidade Liquilândia, que, como muitos outros projetos subsidiados de incentivo ao desenvolvimento agropecuário da Amazônia faliram.

O grupo URSINI transferiu entre os anos de 1979 a 1981 todas as suas empresas a italiana Nazionale Idrocarburi (ENI). A partir de 1979, portanto, a fazenda Suiá-Missu, agora com 500.000 ha foi denominada Liquifarma Agropecuária Suiá-Missu S.A, e pertencia a Liquigás/Liquipar subsidiária da Agip Petroli/ENI.

Em 1989 por dificuldades em manter a infraestrutura (estradas e pastagens) ocasionando a decadência e abandono da Suiá-Missu juntamente com o fim dos incentivos fiscais, a subsidiária Liquigás/Liquipar vendeu ao grupo paulista Garavelo 260.000 ha, que tratou de lotear para revender 20.000 ha ao norte da referida fazenda, local em que o Instituto Nacional de Colonização e Reforma Agrária pretendera no ano de 1987 realizar um projeto de assentamento (Gleba Dom Pedro).

Em 1991 um processo administrativo formalizado pelos Xavante de Marãiwatsédé para identificação do seu território ocorreu na sede da Fundação Nacional do Ìndio (FUNAI) do índio, estando presentes representantes da subsidiária Liquigás/Liquipar e da Agip Petroli/ENI, assessores do Núcleo dos Direitos Indígenas e Centro de Trabalho Indigenista (CTI).

Em janeiro de 1992 um convênio entre a FUNAI e a CTI identificaram em abril por meio de uma proposta cartográfica o território Xavante Marãiwatsédé com 200.000 ha, dos quais aproximadamente 168.000 ha no interior da fazenda Suiá-Missu.

O presidente da ENI acompanhado da subsidiária Agip do Brasil no ano de 1992 declarou publicamente em junho, durante a ECO - 92 Rio que a fazenda Suiá-Missu (250.000 ha no Noroeste do Estado de Mato Grosso seria devolvida aos seus legítimos dono, os Xavante. 
Figura 1 - Esquema da terra indígena Xavante Marãiwatsédé no Estado de Mato Grosso, Brasil declarada pela Nazionale Idrocarburi (ENI) na ECO-92 Rio e porção da terra indígena Xavante Marãiwatsédé na fazenda Suiá-Missu

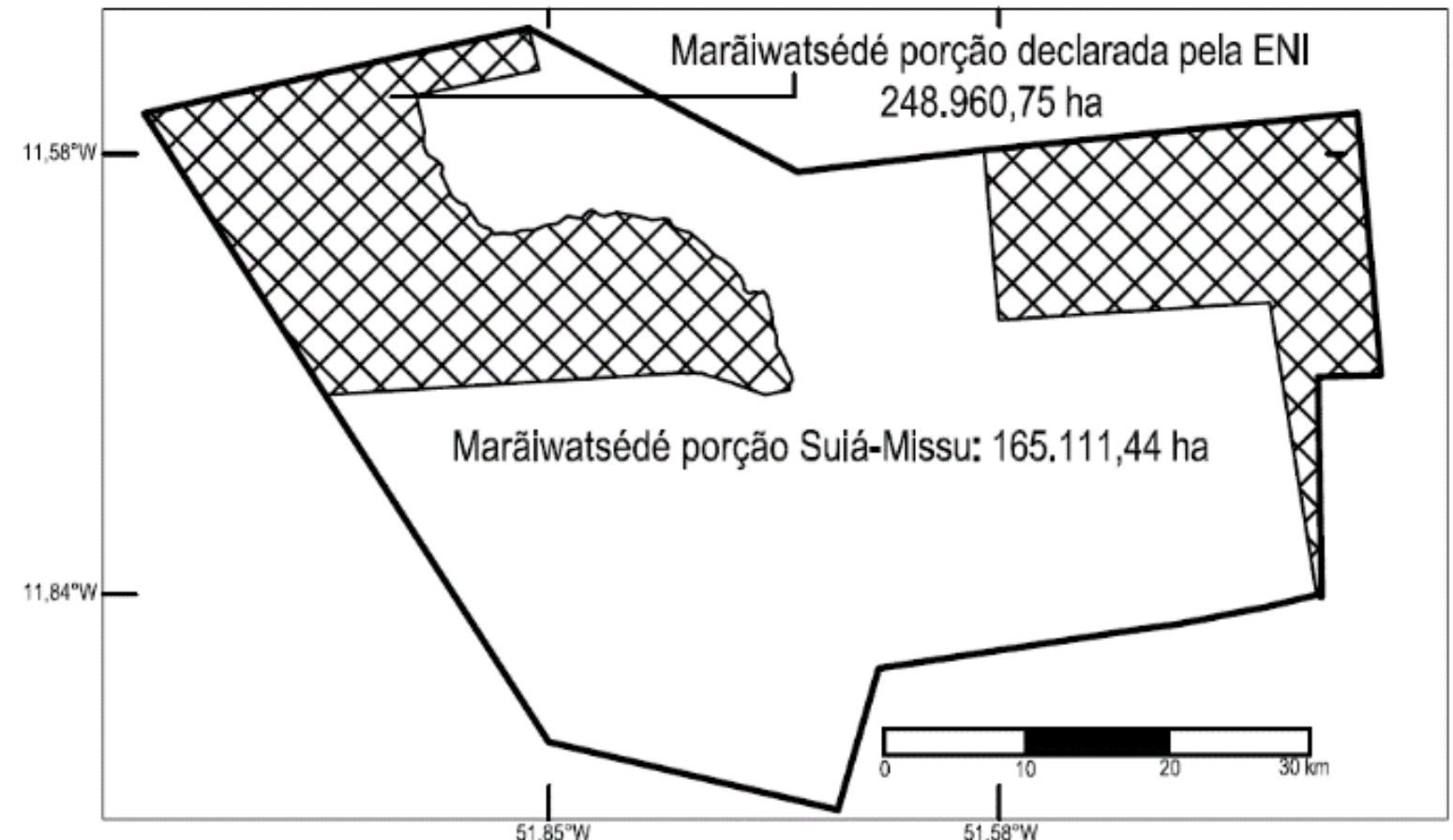

Fonte: adaptado de Paret \& Fanzeres (2012)

A subsidiária brasileira Liquigás/Liquipar não concordara com a restituição das terras aos Xavante e formaram "alianças" com os latifundiários locais e os grupos econômicos do Mato Grosso, e ingressaram como uma ação judicial de reintegração de posse na comarca de São Félix do Araguaia-MT. Imediatamente, financiados por políticos locais e latifundiários com a justificativa de atraso e marasmo à região na presença dos indígenas, centenas de pessoas iniciaram a invasão da referida área.

Uma carta endereçada a Célio Borja (Ministro da Justiça) e Sydney Possuelo (Presidente da FUNAI) por Iara Ferraz do Centro de Trabalho Indigenista e Mariano Mampieri do Campagna Nord/Sud em 17 de junho de 1992 relata em denúncia a primeira tentativa de invasão à fazenda Suiá-Missu. Segundo os denunciantes havia no Posto da Mata um cartaz fixado à parede daquele posto de gasolina convocando "posseiros da Suiá" para uma reunião em 20 de junho às 14 horas, com a presença do prefeito de São Félix do Araguaia e Alto da Boa Vista.

Junto ao cartaz referido no parágrafo anterior encontrava-se um mapa (Figura 2) da Fazenda Suiá-Missu. Coincidentemente, a maior parte das áreas do mapa que foram excluídas da proposta da área indígena a ser demarcada pela FUNAI correspondiam a pastagens e a sede da fazenda, e que deveriam ser "respeitadas" (não invadidas) para 
serem leiloadas em outubro do mesmo ano (Figura 2). Assim, a "área liberada" aos posseiros correspondeu exatamente à proposta da área indígena.

Figura 2 - Propaganda de leilão da fazenda Suiá-Missu e croqui das áreas destinadas a leilão (áreas escuras)

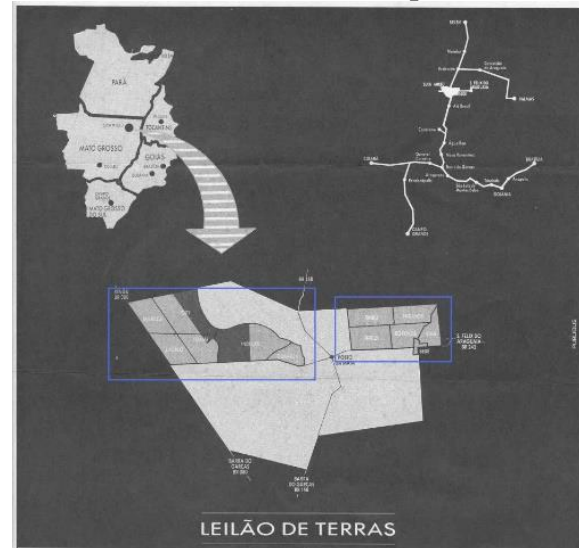

LIQUIFARM AGROPECUÁRIA SUIÁ MISSÚ SIA

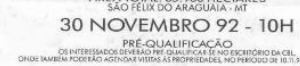

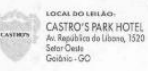

BS] BAMERINDUS

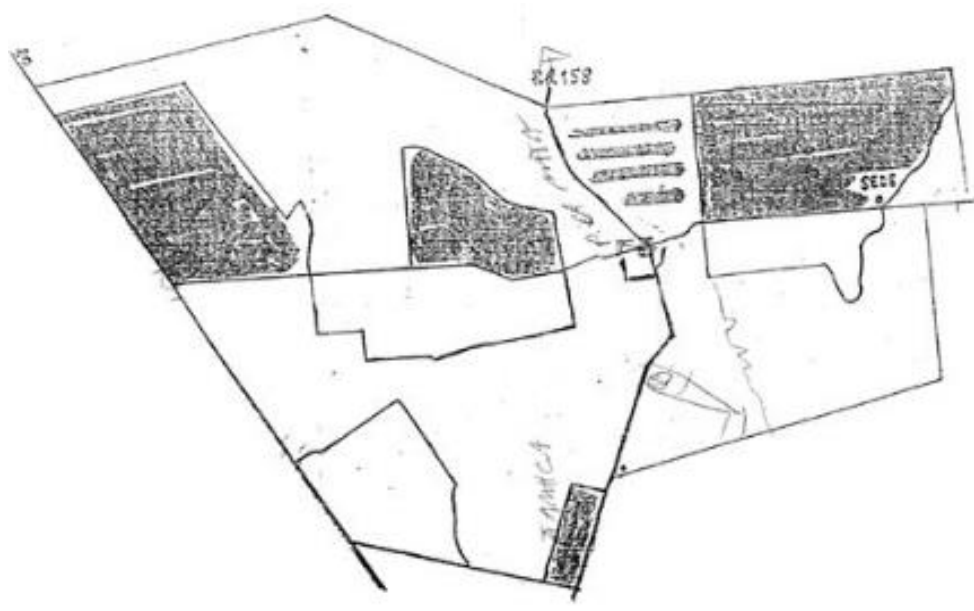

Fonte: Paret \& Fanzeres (2012)

Em agosto de 1992 a FUNAI emite um parecer técnico referente ao reconhecimento público de Marãiwatsédé para cumprimento da etapa posterior do processo administrativo de demarcação da terra indígena. Por meio da Coordenadoria de Defesa dos Direito Indígenas os Xavante ingressaram com uma ação cautelas (1992) preparatória a ação civil pública contra os mandantes da invasão; a terra indígena Marãiwatsédé passou a ser protegida como patrimônio público visando a proteção contra o desmatamento e queimadas.

No final de 1992 o pajé Damião Paridzané vai a Roma em reunião com parlamentares italianos e, em maio de 1993 a Agip Petroli renunciou o domínio sobre a 
Suiá-Missu. Assim, Marãiwatsédé ficou caracterizada como de ocupação tradicional e permanente indígena do povo Xavante nos termos do artigo 231 da Constituição Federal e do artigo 17 da Lei $\mathrm{n}^{\circ} 6.001$ de 19 de dezembro de 1973. A definição dos seus limites foi oficializada na seção 01, página 15 e data 01/10/1993 do Diário Oficial da União (DOU) por meio da portaria declaratória da posse permanente indígena, para efeito de demarcação tendo em vista o disposto no Decreto $\mathrm{n}^{0} 11$, de 18 de janeiro de 1991, combinado com o Decreto $\mathrm{n}^{\circ} 22$, de 19 de fevereiro de 1991 e diante da proposta apresentada pela FUNAI, objetivando a definição de limites da Área Indígena Marãiwatsédé constante do Processo FUNAI/BSB/1318/92.

A homologação da demarcação administrativa da terra indígena Xavante Marãiwatsédé deu-se por meio do Decreto não numerado de 11 de dezembro de 1998 da Presidência da República. Foi registrada no Cartório Regional de Imóveis (CRI) e na Secretaria de Patrimônio da União (SPU) pelo Decreto n ${ }^{0} 1.775$ de 8 de janeiro de 1996. No entanto, de 1993 até a desintrusão na data 28/01/2013 dos “posseiros" muitos conflitos armados ocorreram.

Até meados da desintrusão em 2013 desmatamentos para abertura de pastos e lavouras, incêndios criminosos e caminhões carregados de toras de madeira provenientes da Terra Indígena Marãiwatsédé eram episódios corriqueiros na região Araguaia - Xingu. atualmente Marãiwatsédé tem ainda paisagens compostas por pastos e áreas degradadas resultantes dos anos de invasão sistemática.

Este trabalho objetivou quantificar a área alterada pela ocupação de posseiros em Marãiwatsédé, terra indígena Xavante localizada no Estado de Mato Grosso, Brasil, entre o período 1992 a 2013.

\section{Metodologia}

O local de estudo foi a terra indígena Xavante Marãiwatsédé, com área de 165.770,99 hectares localizada no Estado de Mato Grosso, Brasil, contida suas partes nos municípios São Félix do Araguaia, Alto Boa vista e Bom Jesus do Araguaia (Figura 3), com altitude entre 350 a 350 m. Está inserida na zona de Köppen-Geiger do como Aw (tropical com estação seca), de temperatura média de $19^{\circ} \mathrm{C}$ e temperaturas médias de mínima e máxima de $19^{\circ} \mathrm{C}$ e $35^{\circ} \mathrm{C}$ respectivamente. A precipitação total anual é superior a 1.800. A área delimitada deu-se a partir da Orbita 224, Ponto 68, do Satélite LANSAT 5 . 
Figura 3 - Localização da terra indígena Marãiwatsédé localizada no Estado de Mato Grosso, Brasil entre os municípios de São Félix do Araguaia, Alto Boa vista e Bom Jesus do Araguaia.)

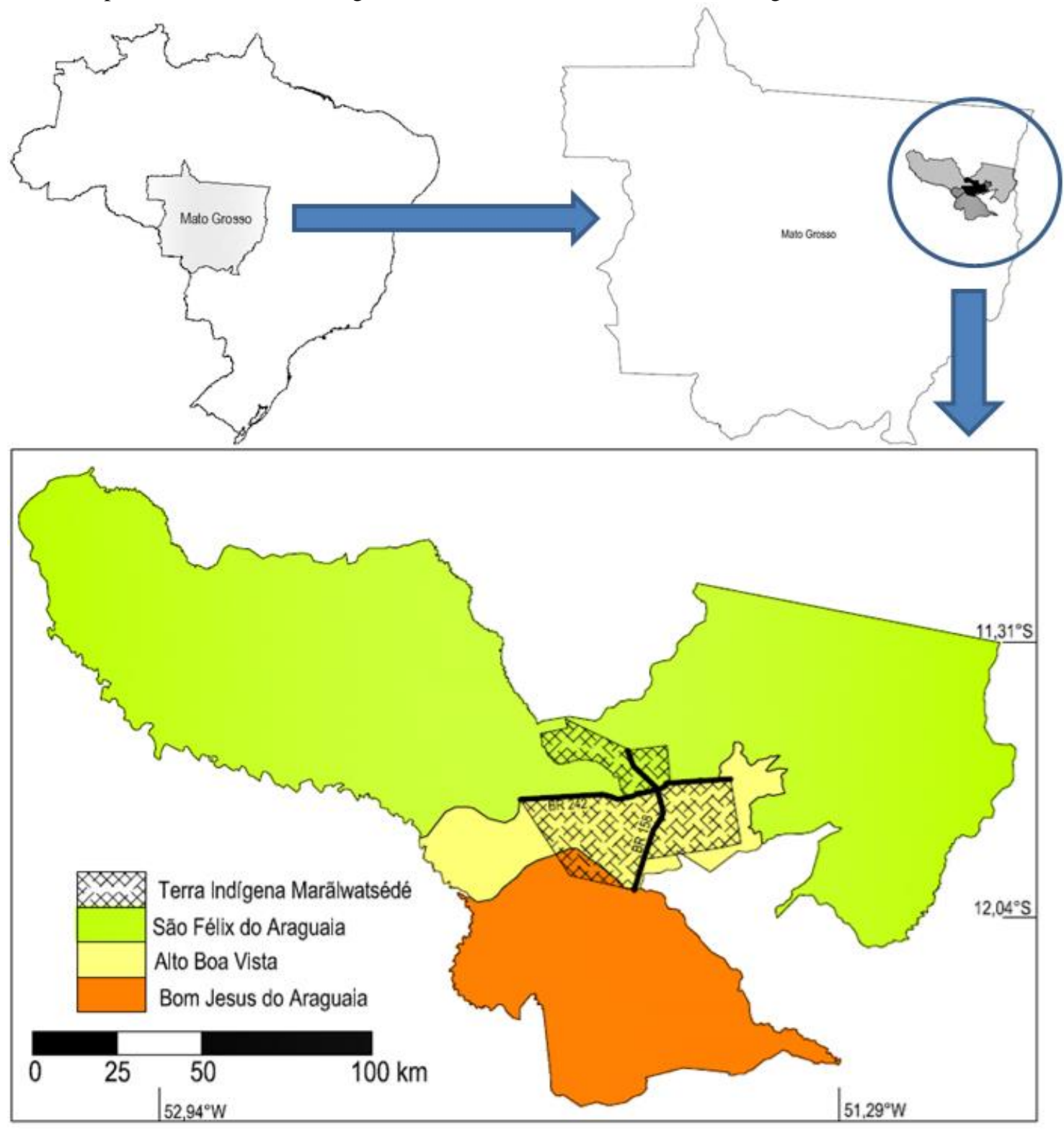

Fonte: autoria própria

A identificação e quantificação da ocupação das áreas da terra indígena Xavante Marãiwatsédé deu-se por meio de mapas temáticos confeccionados no aplicativo computacional SPRING 5.2.8 do Instituto Nacional de Pesquisas Espaciais (INPE) considerando as classes temáticas: complexo vegetativo (Florestas, Mata de galeria, Cerrado típico, Várzeas e áreas alteradas mas em processo de regeneração natural); áreas alteradas (utilizadas com agricultura e/ou pecuária). Ainda, procedeu-se uma segunda classificação para os anos de 2013 e 2017 envolvendo as classes temáticas Mata (mata de galeria, mata ciliar ou cerrado típico), "Em regeneração" (vegetação em processo natural 
e avançado de regeneração) e "Recuperação atrasada" (áreas em que o processo natural de regeneração praticamente não foi iniciado).

O sistema de coordenadas geográficas métrico UTM, sistema geodésico de referência SIRGAS 2000 com o elipsóide GRS80 e datum geocêntrico foram utilizados nas suas configurações. A base de dados georreferenciados de Marãiwatsédé foi fornecida pelo Ministério do Transporte no arquivo digitalizado das terras indígenas.

Na classificação da imagem de satélite foram utilizadas as bandas 3(R) 4(G) 2(B), vermelho, verde e azul, respectivamente, composição esta suficiente para detalhamento das características do solo e também para evidenciar a vegetação natural exigidas no presente trabalho.

A extração de informação em imagens de satélite para reconhecer padrões e objetos homogêneos deu-se por meio de um classificador multiespectral "pixel a pixel" máxima verossimilhança (MAXVER), a qual utilizou apenas a informação espectral isoladamente de cada pixel para achar regiões homogêneas. Para tal, a imagem foi dividida em conjunto de "pixels" contíguos que se espalham bidirecionalmente e que apresentam uniformidade formando regiões que devem corresponder às áreas de interesse da aplicação pela sua segmentação, no processo de crescimento de regiões (agrupamento de dados na qual somente as regiões adjacentes, espacialmente, podem ser agrupadas) (PIZARRO et al., 2001), com valores de similaridades e área do pixel de $12 \mathrm{~m}$ x $15 \mathrm{~m}$.

A classificação da imagem deu-se pelo método semi-automático (supervisionado), com o classificador por região Bhattacharya. "O algoritmo utiliza a distância de Bhattacharya para medir a separabilidade estatística entre cada par de classe espectral” (LEÃO et al., 2007). A separabilidade é calculada por meio da distância média entre as distribuições de probabilidades de classes espectrais.

Com intuito de melhorara a caracterização da área em estudo foi obtido os mapas temáticos de altitude e declividade (Figura 4) da terra indígena Xavante Marãiwatsédé a partir de dados altimétricos de sensores ativos (radar) do SRTM (Shuttle Radar Topography Mission). As imagens SRTM de Marãiwatsédé foram disponibilizadas gratuitamente pela EMPRESA BRASILEIRA DE PESQUISA AGROPECUÁRIA. 
Figura 4 - Mapas de altitude e declividade da terra Indígena Marãiwatsédé obtido a partir de dados de radar, obtidos de sensores a bordo do ônibus espacial Endeavour, no projeto SRTM (Shuttle Radar Topography $\underline{\text { Mission) }}$

Fonte: autoria própria

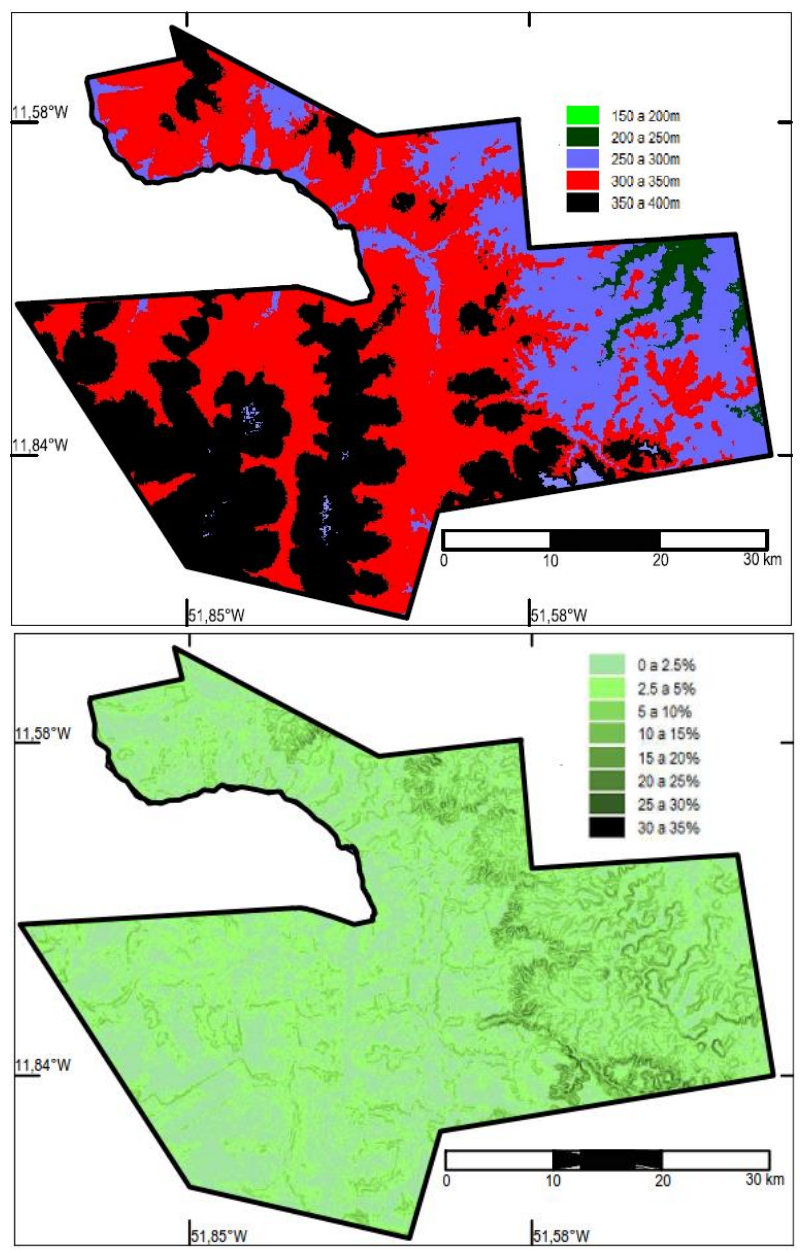

\section{Resultados e Discussão}

No ano de 1992, quando latifundiários locais iniciaram a invasão da terra indígena Marãiwatsédé sob a premissa de que a presença indígena traria atraso e marasmo à região havia lá $23,24 \%$ de terras classificadas "como alteradas" e 76,76\% de complexo vegetativo (Figura 5). Paret \& Fanzeres (2012), em 1992, por meio de uma classificação mais específica da vegetação estabeleceram que $66 \%$ de áreas eram florestas e $11 \%$ cerrados, totalizando 77\% de área preservada em Marãiwatsédé, e somente o restante estava degradado. 
Figura 5 - Na parte superior da figura tem-se a classificação da Terra Indígena Xavante Marãiwatsédé localizada no Estado de Mato Grosso, Brasil como "Complexos vegetativos" e áreas "alteradas" pelo uso agrícola e/ou pecuário. Na parte inferior da figura têm-se as imagens de satélites de referência ao processo de classificação
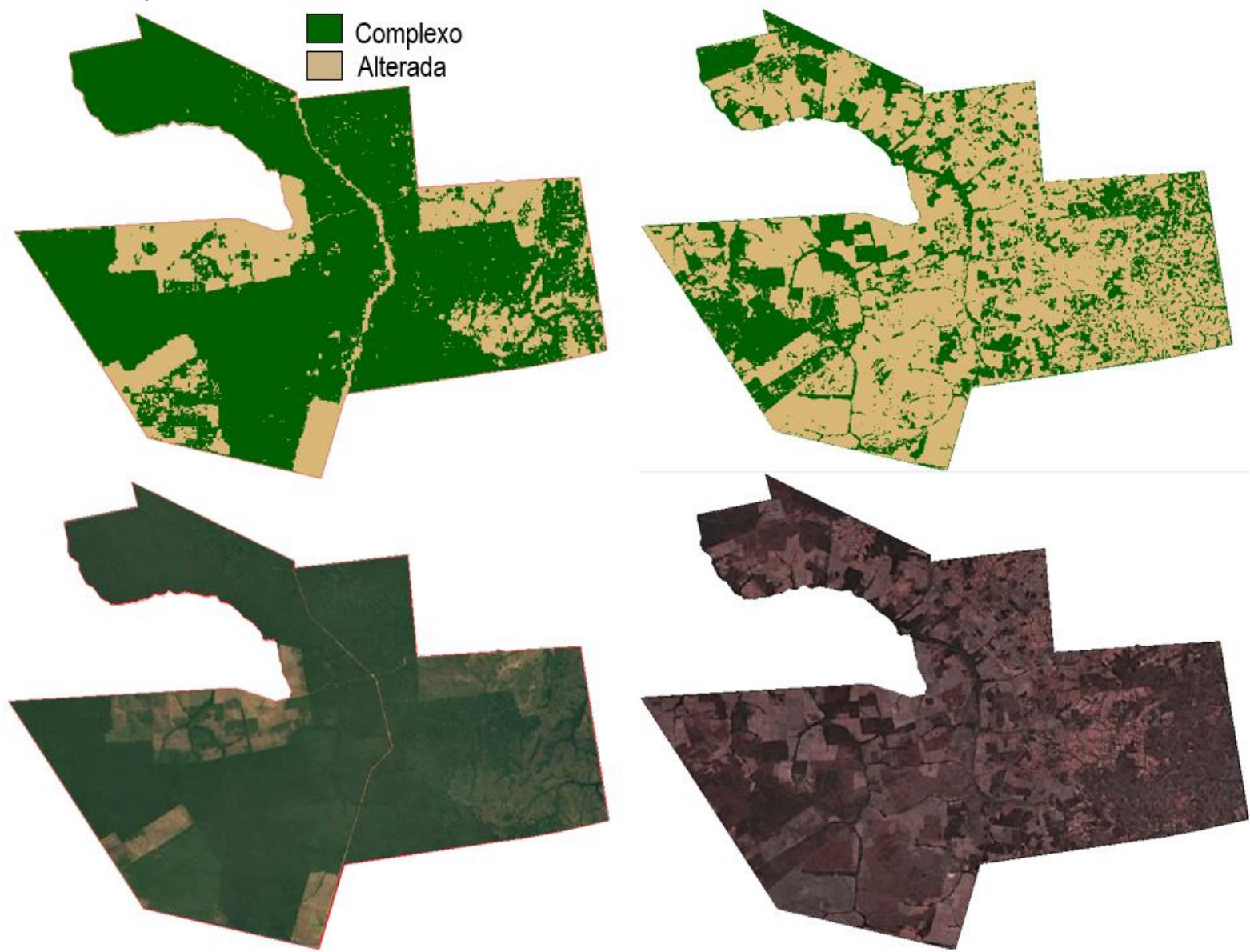

Fonte: autoria própria

No ano da desintrusão, em 2013, a Marãiwatsédé continha 66,64\% das suas áreas alteradas e 33,36\% de complexo vegetativo (Figura 5). A taxa de alteração das áreas de Marãiwatsédé pelos posseiros no referido período foi de 2,07\% ano ${ }^{-1}$, área equivalente a 3.431,45 hectares. Frente ao postulado observou-se que a ocupação de Marãiwatsédé em 1992 por posseiros culminou na redução de 43,40\% do complexo vegetativo inicial.

Segundo dados do Projeto de Monitoramento do Desmatamento na Amazônia Legal (PRODES), do INPE, 51,14\% da Terra Indígena Marãiwatsédé já havia sido desmatada até 2001, ano esse de maior incremento percentual de desmatamento. Nos anos de 2009, 2011 e 2014 a PRODES estimou 69,70\%, 71,52\% e 72,34\% respectivamente de desmatamento em Marãiwatsédé.

Por meio do mapa temático da figura 6, no ano de 2013 - ano da desintrusão constatou-se que a área de mata (mata de galeria e ciliar) da Terra Indígena Marãiwatsédé foi de $6,72 \%$, a área em recuperação natural vegetativa de $37,58 \%$ e a área com 
recuperação vegetativa natural em atraso de 55,70\%. Possivelmente para o ano de 2013, como foi o ano em que havia atividade agrícola e/ou pecuária na referida terra indígena o valor citado de área em recuperação natural vegetativa foi expressivamente influenciado pela presença de pastagens "sujas", ou seja, presença de animais em uma área de pastejo não manejada estabelecida em tempos anteriores pela remoção do Cerrado típico.

Figura 6 - Classificação com intuito de avaliação da recuperação natural vegetativa da Terra Indígena Xavante Marãiwatsédé localizada no Estado de Mato Grosso, Brasil em dezembro de 2013 (a direita) e em dezembro de 2016 (a esquerda)

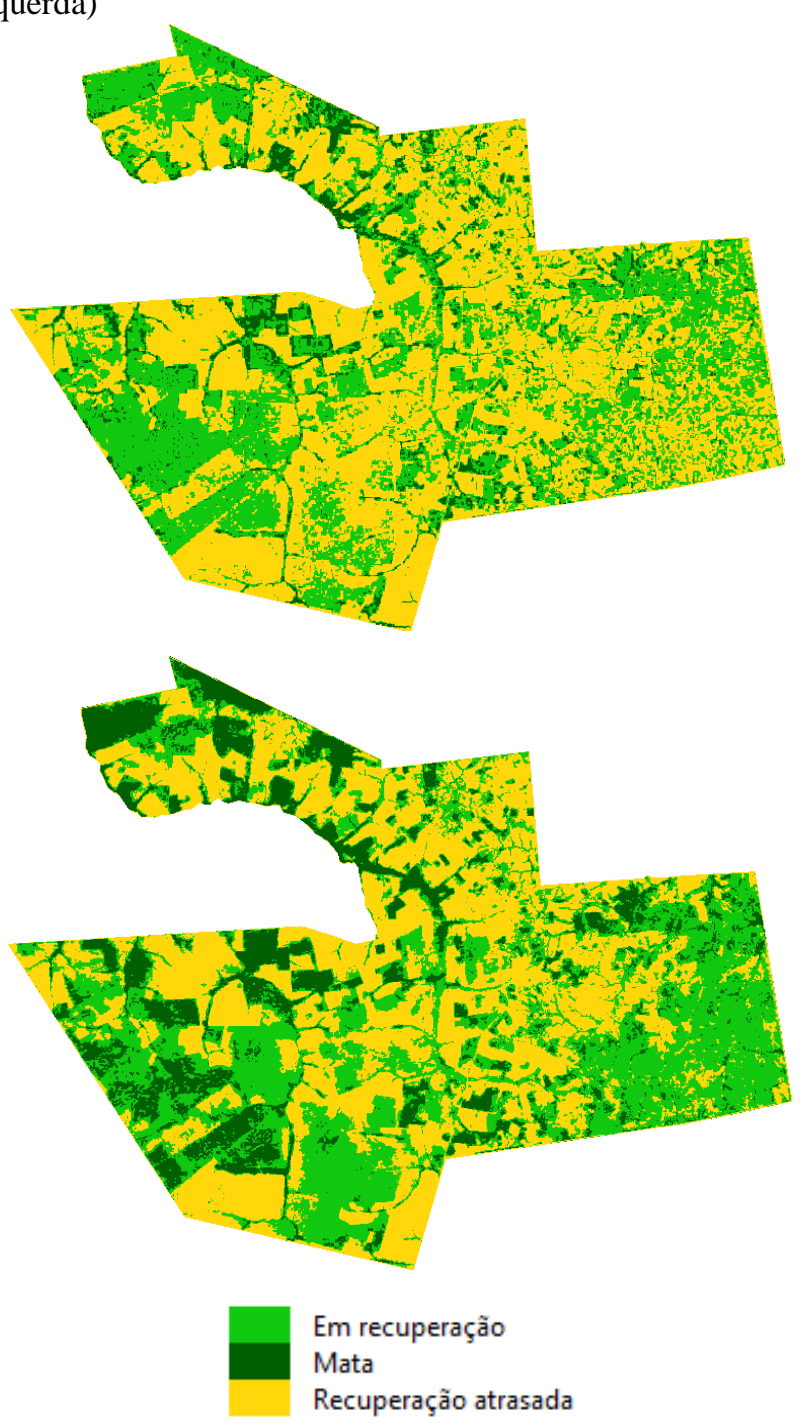

Fonte: autoria própria

Como esperado, passados três anos após desintrusão, em 2016, houve aumento percentual de 2,5 vezes sobre a área de mata em Marãiwatsédé (17,08\%) em relação a 2013. A área em recuperação natural vegetativa em 2016 foi de 38,57\%, valor próximo aquele observado em 2013. Para a área com recuperação vegetativa natural atrasada o 
valor observado em 2016 foi de 44,35\%, sendo este 1,3 vezes menor daquele observado em 2013.

O “avanço" pouco expressivo entre 2013 a 2016 de áreas em recuperação natural vegetativa está relacionado, possivelmente, às frequentes “queimadas” em extensas áreas de Marãiwatsédé entre os mese de maio a agosto, dificultando o reestabelecimento da vegetação natural. Segundo OPAN (Operação Amazônia Nativa) e ISA (Instituto Socioambiental), Marãiwatsédé teve mais de $47 \%$ de sua área queimada entre maio e agosto por ações criminosas que iniciaram-se a partir da desintrusão em 2013 de posseiros.

Figura 7 - Incêndios em Marãiwatsédé indicativo de dificuldade regenerativa natural da vegetação

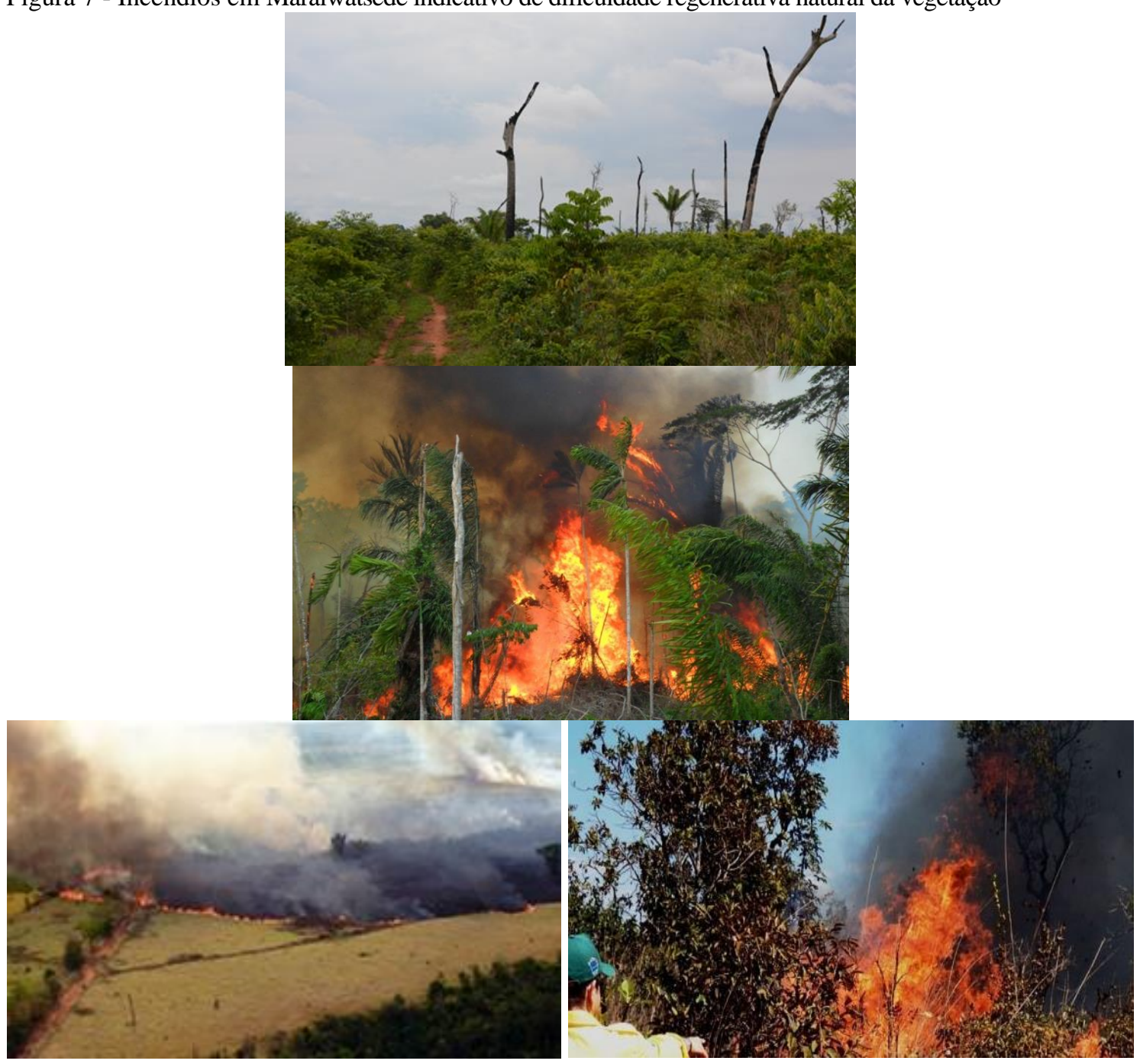

Fonte: Rafael Govari

As áreas de cerrado no Brasil têm estreita relação com incêndios, pois grande parte das espécies vegetais nelas existentes coevoluíram morfologicamente e/ou fisiologicamente na presença do fogo, que passou a ser um elemento essencial para a 
manutenção da biodiversidade (HARDESTRY et al., 2005; 2009; SIMON et al., 2009; PIVELLO, 2011). A retirada ou introdução excessiva do fogo portanto, altera o equilíbrio em áreas de cerrado.

Uma maior freqência de incêndios florestais na região de transição entre a florestas e áreas de cerrado - fato este ocorrente dentro dos limites da terra indígena Marãiwatsédé - proporciona segundo Silvério et al. (2013) invasão de gramineas nativas em ecossistemas florestais. A referida "invasão" de gramíneas dá-se por inúmeros fatores insidentes sobre a sobrevivência e regeneração natural das florestas, como por exemplo alteração da a diversidade e fluxo da micro e macrofauna disseminadora em processos diretos e/ou indireto das sementes, alterações na dinâmica de ciclagem (mobilização e mineralização) de nutrientes bem como sua disponibilidade no solo às plantas, umidade do solo, evapotranspiração e etc (NARDOTO \& BUSTAMANTE, 2003; QUESADA et al., 2004; PIVELLO et al., 2010; OLIVEIRAS et al., 2013).

Segundo RSX (2014) e ISA (2017a), em 2014, sem recursos naturais e com ajuda mínima governamental os Xavante, juntamente com a Associação Rede de Sementes do Xingu sediada em Canarana-MT criaram em 2011 um grupo (Pi'õ Rómnha/ Ma'ubumrõi'wa) de 35 mulheres coletoras de sementes. As sementes comercializadas são importante fonte de renda aqueles indígenas. Ainda, com a atividade coletora, e de acordo com suas possibilidades, os Xavante reflorestaram um hectare de área degradada com a semeadura a lanço, e até o final de 2014 previam o reflorestamento de mais três hectares. Em 2017 o número de coletaras de sementes aumentou, sendo de 60 mulheres ISA (2017b).

Frente ao postulado, e sabendo do valor inestimado que tem a vegetação original preservada aos povos indígenas na qual são dependentes pela retirada da caça, obtenção de remédios naturais e matéria prima dos abrigos, conservação dos mananciais bem como da direta relação dos aspectos culturais e históricos que a natureza tem com suas vidas, a preservação e recomposição das espécies vegetais em Marãiwatsédé é decisiva a existências dos Xavante.

\section{Conclusões}

No ano de 1992 havia na terra indígena Marãiwatsédé 23,24\% de áreas alteradas por uso de atividades agrícolas e/ou pecuárias, e 76,76\% de complexo vegetativo. No ano da sua desintrusão, em 2013, a referida terra indígena continha 66,64\% de áreas alteradas e $33,36 \%$ de complexo vegetativo. 
A taxa de alteração das áreas de Marãiwatsédé no período entre 1992, ano da ocupação por posseiros, e 2013, ano da desintrusão foi de $2,07 \% \mathrm{ano}^{-1}$, área equivalente a 3.431,45 hectares. Com isso constatou-se que a ocupação de Marãiwatsédé culminou na redução de $43,40 \%$ do complexo vegetativo inicial.

\section{Referências}

EMPRESA BRASILEIRA DE PESUISA AGROPECUÁRIA (2012). Recuperado em 11 de maio, 2017, de http://www.relevobr.cnpm.embrapa.br/download/index.htm

HARDESTY, J.M.R.; FULKS, W. Fire, ecosystems, and people: a preliminary assessment of fire as a global conservation issue. The George Wright Forum. v.22, p. 78-87, 2005.

ISA (Instituto Socio Ambiental). Rede de Sementes do Xingu visita aldeia Marãiwatsédé. Disponível em: https://www.socioambiental.org/pt-br/blog/blog-doxingu/rede-de-sementes-do-xingu-visita-aldeia-maraiwatsede. Acesso: 26 de maio de 2017a.

ISA (Instituto Socio Ambiental). Rede de Sementes do Xingu visita aldeia Marãiw Incêndios criminosos impedem regeneração florestal na Terra Indígena Marãiwatsédé (MT). Disponível em: https://www.socioambiental.org/pt-br/noticiassocioambientais/incendios-criminosos-impedem-regeneracao-florestal-na-terraindigena-maraiwatsede-mt. Acesso: 26 de maio de 2017b.

LEÃO, C.; KRUG, L.A.; KAMPEL, M.; FONSECA, L.M.G. Avaliação de métodos de classificação em imagens TM/Landsat e CCD/CBERS para o mapeamento do uso e cobertura da terra na região costeira do extremo sul da Bahia. In XIII Simpósio Brasileiro de Sensoriamento Remoto, 2007, Florianópolis-SC. Anais... XIII Simpósio Brasileiro de Sensoriamento Remoto, 2007. v.1 p. 939-946. 
NARDOTO, G.B.; BUSTAMANTE, M.M.C.; Effects of fire on soil nitrogen dynamics and microbial biomass in savannas of Central Brazil. Pesquisa Agropecuária Brasileira, v.38, n.8, p. 955-962, 2003.

OLIVERAS, I.; MEIRELLES, S.T.; HIRAKURI, V.L.; FREITAS, C. R.; MIRANDA, H.S.; PIVELLO, V.R. Effects of fire regimes on herbaceous biomass and nutrient dynamics in the Brazilian savanna. International Journal of Wildland Fire, v.22, p.368-380, 2013.

PARET, C.G.; FANZERES, A. (Org.). Marãiwatsédé: terra de esperança. Cuiabá: ANSAOPAN, 2012.

PIVELLO, V.R.; OLIVERAS, I.; MIRANDA, H.S.; HARIDASAN, M.; SATO, M.N.; MEIRELLES, S.T. Effect of fires on soil nutrient availability in an open savanna in Central Brazil. Plant and Soil, v.337, p.111-123, 2010.

PIVELLO, V.R. The use of fire in the Cerrado and Amazonian rainforests of Brazil: past and present. Fire Ecology, v.7, p.24-39, 2011.

PIZARRO, P.; COMUNELLO, E.; MANTELLI, S. Segmentação por Crescimento de Regiões. In: Aldo Von Wangenheim, Eds. Introdução à visão computacional. New York, Taylor e Francis, 2001. p. 35-64.

QUESADA, C. A.; MIRANDA, A. C.; HODNETT, M. G.; SANTOS, A. J. B.; MIRANDA, H. S.; BREYEr, L. M. Seasonal and depth variation of soil moisture in a burned open savanna (campo sujo) in central Brazil. Ecological Applications, v.14, n.4, p.33-41, 2004.

RSX (Rede de Sementes do Xingu). Sementes do Xingu: Rede de Sementes do Xingu funda associação e avança rumo a novos desafios. Informativo sobre a Rede de Sementes do Xingu, 2014. 7p.

SILVÉRIO, D.V.; BRANDO, P.M.; BALCH, J.K; PUTZ, F.E.; NEPSTAD, D.C.; OLIVEIRA-SANTOS, C.; BUSTAMANTE, M.M.C. Testing the Amazon savannization 
hypothesis: fire effects on invasion of a neotropical forest by native cerrado and exotic pasture grasses. Philosophical Transactions of the Royal Society B, v.368, n.1, 619, p.20427, 2013.

SIMON, M.F.; GRETHER, R.; QUEIROZ, L.P.; SKEMA, C.; PENNINGTON, T.R.; HUGHES, C.E. Recent assembly of the Cerrado, a neotropical plant diversity hotspot, by in situ evolution of adaptations to fire. Proceedings of the National Academy of Sciences, v.106, n.48, p.20359- 20364, 2009. 